\title{
Alpha-1-fucosidase as a prognostic indicator for hepatocellular carcinoma following hepatectomy: a large-scale, long-term study
}

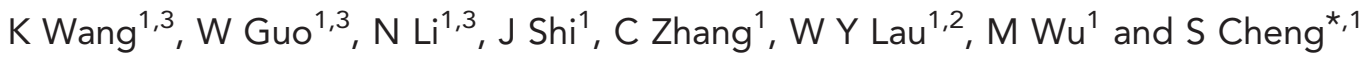 \\ ${ }^{1}$ Eastern Hepatobiliary Surgery Hospital, The Second Military Medical University, Shanghai, China and ${ }^{2}$ Faculty of Medicine, \\ The Chinese University of Hong Kong, Shatin, Hong Kong SAR, China
}

Background: Preoperative alpha-L-fucosidase (AFU) has been used as a diagnostic biomarker for hepatocellular carcinoma (HCC), but its role as a prognostic predictor after partial hepatectomy has not been well defined. The study aimed to investigate the prognostic significance of preoperative serum AFU for HCC patients after hepatic resection.

Methods: A retrospective training data set and a prospective validation data set were used to evaluate the prognosis of $\mathrm{HCC}$ after partial hepatectomy. A total of 669 patients with histopathologically confirmed HCC were enrolled. Univariate and multivariate analyses were used to identify the prognostic significance of preoperative serum AFU.

Results: The retrospective training data set showed a preoperative $\mathrm{AFU}>35 \mathrm{ul}^{-1}$ should be used. The prospective validation data set showed preoperative AFU was an independent prognostic factor of overall survival $(O S)(P=0.008$; hazard ratio: $2.333 ; 95 \%$ confidence interval: 1.249-4.369). Patients with a preoperative AFU $>35 \mathrm{ul}^{-1}$ had a lower recurrence-free survival rate and an OS rate than those with $\mathrm{AFU} \leqslant 35 \mathrm{ul}^{-1}$, and they have a higher tendency to form macrovascular invasion. Furthermore, the prognostic significance of $\mathrm{AFU}>35 \mathrm{ul}^{-1}$ could also be applied to patients with alpha-fetoprotein levels of $\leqslant 400 \mathrm{ng} \mathrm{ml}^{-1}$.

Conclusions: Preoperative serum AFU is a prognostic predictor of HCC.

Hepatocellular carcinoma (HCC) is a common cancer with a dismal prognosis. Although partial hepatectomy is the most widely practiced form of therapy aiming at cure, the tumour resectability at diagnosis is low. The rate of tumour recurrence after operation is high, which ranges from $60 \%$ to $100 \%$ at 5 years (Nagasue et al, 1993; Ercolani et al, 2003; Tang et al, 2004). There is still no effective means to predict tumour recurrence after partial hepatectomy. Although risk factors associated with post-operative HCC recurrence have been identified, the heterogeneity of HCC renders early detection of post-operative tumour recurrence a major challenge.

Alpha-L-fucosidase (AFU), a liposomal enzyme present in all mammalian cells and involved in the degradation of a variety of fucose-containing fucoglycoconjugates, has been proposed as a promising tumour marker in the diagnosis of HCC (Deugnier et al, 1984; Leray et al, 1989). Alpha-L-fucosidase has been suggested to be able to diagnose $85 \%$ of patients with HCC 6 months before the detection by ultrasonography (El-Houseini et al, 2001). Although some studies suggested that AFU can be used to detect recurrent HCC after interventional therapies (Malaguarnera et al, 2010; Fawzy Montaser et al, 2012), the use of preoperative serum AFU as a clinical prognostic predictor of HCC has not been reported.

In the first part of this study, a retrospective study was conducted on a group of patients who received partial hepatectomy for HCC to determine the best cut-off value of preoperative serum $\mathrm{AFU}$ to be used as a prognostic indicator to determine long-term recurrence-free survival (RFS) and overall survival (OS) after surgery. The cut-off value of this training cohort for AFU was then applied to an independent prospective cohort at the second stage of the study to validate the prognostic value of AFU (the validation cohort) on the RFS and OS after surgery.

\footnotetext{
*Correspondence: Dr S Cheng; E-mail: chengshuqun@aliyun.com
}

${ }^{3}$ These authors contributed equally to this work.

Received 20 July 2013; revised 22 October 2013; accepted 22 January 2014; published online 25 February 2014 


\section{MATERIALS AND METHODS}

Patients and design. From 2002 to 2010, all patients who underwent partial hepatectomy for HCC at the Eastern Hepatobiliary Surgery Hospital in Shanghai were considered to be included into this study. The data of patients from 2002 to 2007 were collected retrospectively and were used for the training cohort. The patients since 2008-2010 were recruited in a prospective study and were used as the validation cohort. Only patients who met the following criteria were included: (1) no previous treatment for HCC, (2) no other malignancies, (3) undergoing curative resection, defined as complete macroscopic removal of the tumour (Poon et al, 2002), (4) HCC was confirmed histologically in the resected specimens.

The tumour stage was determined according to the Barcelona Clinic Liver Cancer (BCLC) staging system (Bruix and Sherman, 2011). Written informed consent was obtained from all the patients. The study was approved by the Ethics Committee of the Eastern Hepatobiliary Surgery Hospital.

Serum AFU activity. Serum AFU activity was measured as previously described (Othman et al, 2011) using 7600 Clinical Analyzer made by Hitachi High-Technologies (Tokyo, Japan). The AFU test kit was from BQKITS (catalogue number: BQ082AEALD). Serum from all fasting subjects were stored at $-20^{\circ} \mathrm{C}$ and assayed within 30 days after collection because AFU activity levels are known to decrease after this period (Zielke et al, 1972).

Follow-up and survival analyses. Post-operative patient surveillance was performed as described previously (Yang et al, 2008). A diagnosis of recurrence was based on computed tomography and/or magnetic resonance imaging, digital subtraction angiography and raised serum $\alpha$-fetoprotein (AFP) level, with or without histological confirmation. When recurrent HCC was diagnosed, the patients were actively treated with radiofrequency ablation, percutaneous ethanol injection, transarterial chemoembolisation or repeat liver resection, according to the general condition of the patient, the underlying liver functional status and the number and location of HCC recurrence. Recurrence-free survival was defined as the interval (in months) between partial hepatectomy and the diagnosis of HCC recurrence (Llovet et al, 2008), using either intrahepatic recurrence or extrahepatic metastasis as end points (Yang et al, 2010). Overall survival was defined as the interval (in months) from the date of partial hepatectomy to the date of the death (Yang et al, 2010). This study was censored on 31 December 2012.

Statistical analyses. The cut-off prognostic value for OS obtained in the training cohort was estimated by the X-tile 3.6.1 software (Yale University, New Haven, CT, USA) (Camp et al, 2004; Sun et al, 2013). The receiver operating characteristic analysis confirmed this level to be the optimal cut-off. It was, therefore, used in the analyses for the validation cohort.

A total of 15 clinical pathologic and biological variables were selected for further analysis. The differences in the categorical variables were evaluated using chi-square test between the training cohort and the validation cohort. Fisher's exact probability test was used to compare the dynamic changes of AFU levels after surgery. Survival was analyzed by the Kaplan-Meir method and survival curves were compared by the log-rank test. Univariate and multivariate analyses were based on the Cox proportional. Spearman correlation coefficient was used to determine significant correlations among AFU level and AFP level. A value of $P<0.05$

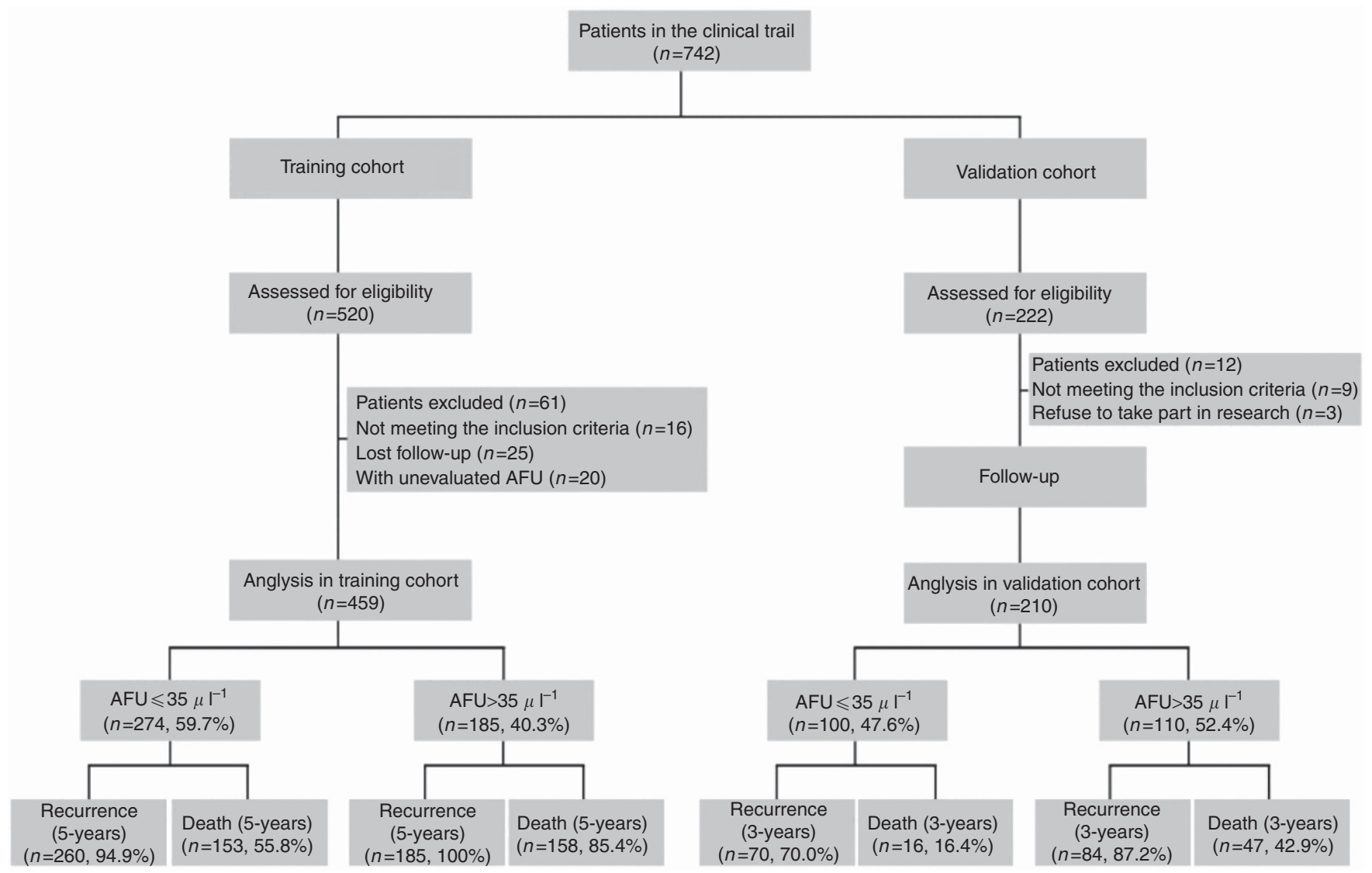

Figure 1. Study flow chart: inclusion criteria, exclusion criteria, and outcome. 
was considered statistically significant. The analysis was performed with the SPSS for Windows 20.

\section{RESULTS}

Patient characteristics. From 2002 to 2007 (the training cohort period), there were 520 patients who received partial hepatectomy for HCC in our centre. The corresponding figure for 2008-2010 (the validation cohort period) was 222 patients. After exclusion, 669 patients were finally enrolled in the analysis (459 and 210 in the training cohort and the validation cohort, respectively). The following patients were excluded from the final analysis: not meeting all the inclusion criteria (16 and 9 for the training cohort and the validation cohort, respectively), lost to follow-up (25 and 0 for the training cohort and the validation cohort, respectively), unevaluable AFU (20 and 0 for the training cohort and the validation cohort, respectively), refusal to take part in the research (3 for the validation cohort). The flow chart is shown in Figure 1.

The characteristics of the participants in the training and the validation cohorts are shown in Table 1 and Supplementary Table S1. There was no significant difference in age and sex between the training and validation cohorts. In the training cohort, there were more patients with hepatitis B surface antigen ( $\mathrm{HBsAg}$ ) positivity than in the validation cohort $(92.4 \%$ vs $85.7 \%$, respectively; $P=0.011$ ). In the validation cohort, there were significantly fewer patients with alanine aminotransferase, or ALT $>44 \mathrm{ul}^{-1}$ than in the training cohort $(44.3 \%$ vs $56.5 \%$, respectively; $P=0.005)$. Serum AFP level was well balanced between the training and validation cohorts. There were fewer patients with AFU $>35 \mathrm{ul}^{-1}$ in the training cohort than in the validation cohort $(40.3 \%$ vs $52.4 \%$, respectively; $P=0.004)$. The tumour characteristics, such as tumour size, tumour number, presence/absence of macrovascular invasion, BCLC stages were similar between the two cohorts.

The cut-off prognostic value for AFU. The cut-off prognostic value for OS obtained in the training cohort was estimated by the X-tile 3.6.1 software (Yale University, New Haven, CT, USA) (Camp et al, 2004; Sun et al, 2013), The results indicated a serum AFU value of $35 \mathrm{ul}^{-1}$ to have the most significant predicting value on OS $(P<0.0001, \log$-rank chi-square value $=63.6758$, relative risks of $\mathrm{AFU} \leqslant 35 \mathrm{ul}^{-1} / \mathrm{AFU}>35 \mathrm{ul}^{-1}, 1.0 / 1.44$; Supplementary Figure S1).

Survival analysis. On the day this study was censored, 601 patients had developed tumour recurrence $(n=447$, or $97.4 \%$ and $n=154$, or $73.3 \%$ for the training cohort and the validation cohort, respectively), 406 patients had died of $\mathrm{HCC}(n=342$, or $74.5 \%$ and $n=64$, or $30.5 \%$ for the training cohort and the validation cohort, respectively), whereas 195 patients were surviving but with HCC disease and 68 patients were surviving without the disease. The median follow-ups were 38.6 months (95\% confidence interval (CI), 33.4-43.1 months) and 30.8 months (95\% CI, 28.0-33.3 months) for the training cohort and the validation cohort, respectively. The 1- and 3-year RFS rates were $44.9 \%, 10.7 \%$ for the training cohort, and $48.5 \%, 26.2 \%$ for the validation cohort. The 1- and 3-year OS were $81.9 \%, 53.4 \%$ for the training cohort and $83.8 \%, 69.6 \%$ for the validation cohort, respectively. The 5-year RFS and OS for the training cohort were $3.1 \%$ and $32.2 \%$, respectively. The follow-up was too short to determine the 5 -year RFS and OS for the validation cohort (Supplementary Figure S2).

On univariate analysis of the training cohort and the validation cohort, and/or on Cox's multivariate analysis by merging the two data sets (Table 2, Supplementary Tables S2 and S3), the preoperative AFU level was an independent risk factor of postoperative RFS and OS $(P=0.001$; hazard ratio $(\mathrm{HR}): 1.369 ; 95 \%$
Table 1. Baseline characteristics of study participants in the training and validation data sets

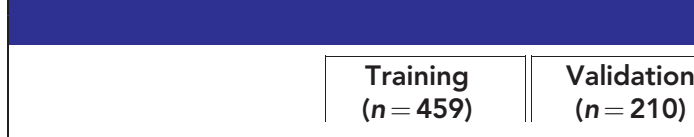

\begin{tabular}{|c|c|c|c|c|c|}
\hline Variables & No. & $\%$ & No. & $\%$ & $\mathrm{P}$-value \\
\hline Age (years) & & & & & 0.451 \\
\hline$\leqslant 50$ & 258 & 56.2 & 111 & 52.9 & \\
\hline$>50$ & 201 & 43.8 & 99 & 47.1 & \\
\hline Sex & & & & & 0.259 \\
\hline Male & 406 & 88.5 & 179 & 85.2 & \\
\hline Female & 53 & 11.5 & 31 & 14.8 & \\
\hline $\mathrm{HbsAg}$ & & & & & 0.011 \\
\hline Positive & 424 & 92.4 & 180 & 85.7 & \\
\hline Negative & 35 & 7.6 & 30 & 14.3 & \\
\hline Total bilirubin $\left(\mathrm{mmoll}^{-1}\right)$ & & & & & 0.215 \\
\hline$\leqslant 18.8$ & 300 & 65.4 & 148 & 70.5 & \\
\hline$>18.8$ & 159 & 34.6 & 62 & 29.5 & \\
\hline Albumin $(\mathrm{g} / \mathrm{l})$ & & & & & 0.370 \\
\hline$\leqslant 34$ & 19 & 4.1 & 5 & 2.4 & \\
\hline$>34$ & 440 & 95.9 & 205 & 97.6 & \\
\hline $\operatorname{ALT}\left(u I^{-1}\right)$ & & & & & 0.005 \\
\hline$\leqslant 44$ & 200 & 43.5 & 117 & 55.7 & \\
\hline$>44$ & 259 & 56.5 & 93 & 44.3 & \\
\hline Tumour size $(\mathrm{cm})$ & & & & & 0.108 \\
\hline$\leqslant 5$ & 200 & 43.6 & 77 & 36.7 & \\
\hline$>5$ & 259 & 56.4 & 133 & 63.3 & \\
\hline Tumour number & & & & & 0.511 \\
\hline Single & 425 & 92.6 & 198 & 94.3 & \\
\hline Multiple & 34 & 7.4 & 12 & 5.7 & \\
\hline GGT $\left(u I^{-1}\right)$ & & & & & 0.201 \\
\hline$\leqslant 64$ & 172 & 37.5 & 90 & 42.9 & \\
\hline$>64$ & 287 & 62.5 & 120 & 57.1 & \\
\hline AFU $\left(u I^{-1}\right)$ & & & & & 0.004 \\
\hline$\leqslant 35$ & 274 & 59.7 & 100 & 47.6 & \\
\hline$>35$ & 185 & 40.3 & 110 & 52.4 & \\
\hline $\operatorname{ALP}\left(\left.u\right|^{-1}\right)$ & & & & & 0.062 \\
\hline$\leqslant 129$ & 324 & 70.6 & 163 & 77.6 & \\
\hline$>129$ & 135 & 29.4 & 47 & 22.4 & \\
\hline $\operatorname{AFP}\left(\mathrm{ng} \mathrm{ml}^{-1}\right)$ & & & & & 0.241 \\
\hline$\leqslant 400$ & 248 & 54.0 & 124 & 59 & \\
\hline$>400$ & 211 & 46.0 & 86 & 41 & \\
\hline Macrovascular invasion & & & & & 0.466 \\
\hline Presence & 65 & 14.2 & 25 & 11.9 & \\
\hline Absence & 394 & 85.8 & 185 & 88.1 & \\
\hline Liver cirrhosis & & & & & 0.764 \\
\hline Yes & 355 & 77.3 & 165 & 78.6 & \\
\hline No & 104 & 22.7 & 45 & 21.4 & \\
\hline BCLC stages & & & & & 0.585 \\
\hline $0+A$ & 375 & 81.7 & 176 & 83.8 & \\
\hline$B+C$ & 84 & 18.3 & 34 & 16.2 & \\
\hline
\end{tabular}

Abbreviations: AFP = alpha-fetoprotein; $A F U=$ alpha-fucosidase; $A L P=$ alkaline phosphatase; $\mathrm{ALT}=$ alanine aminotransferase; $\mathrm{BCLC}=$ Barcelona Clinic Liver Cancer staging system; $\mathrm{GGT}=\gamma$-glutamyl transpeptidase; $\mathrm{HbsAg}=$ hepatitis $\mathrm{B}$ surface antigen. Data are number or number (\%), unless otherwise indicated. 
Table 2. Univariate analysis or multivariate analysis based on the Cox proportional hazard regression model for RFS and OS in patients enrolled in training cohort or validation cohort or Two datasets merging

Univariate analysis

Multivariate analysis

\begin{tabular}{|c|c|c|c|c|}
\hline Variables & HR $(95 \% \mathrm{Cl})$ & P-value & HR (95\% Cl) & P-value \\
\hline \multicolumn{5}{|l|}{ Training cohort-RFS } \\
\hline $\begin{array}{l}\text { AFU }\left(\leqslant 35 \text { vs }>35 \mathrm{ul}^{-1}\right) \\
\text { Tumour size }(\leqslant 5 \text { vs }>5 \mathrm{~cm}) \\
\text { GGT }\left(\leqslant 64 \text { vs }>64 \mathrm{ul}^{-1}\right) \\
\text { AFP }\left(\leqslant 400 \text { vs }>400 \mathrm{ng} \mathrm{ml}^{-1}\right) \\
\text { Macrovascular invasion } \\
\text { ALP }\left(\leqslant 129 \text { vs }>129 \mathrm{ul}^{-1}\right)\end{array}$ & $\begin{array}{l}2.277(1.864-2.780) \\
2.055(1.693-2.494) \\
1.527(1.258-1.854) \\
1.239(1.028-1.492) \\
1.498(1.146-1.958) \\
1.328(1.084-1.627)\end{array}$ & $\begin{array}{r}<0.001 \\
<0.001 \\
<0.001 \\
0.024 \\
0.003 \\
0.006\end{array}$ & $\begin{array}{l}1.738(1.383-2.185) \\
1.663(1.331-2.079) \\
1.159(0.933-1.440) \\
0.905(0.741-1.106) \\
1.248(0.946-1.646) \\
0.998(0.802-1.241)\end{array}$ & $\begin{array}{r}<0.001 \\
<0.001 \\
0.183 \\
0.330 \\
0.117 \\
0.982\end{array}$ \\
\hline
\end{tabular}

Training cohort-OS

\begin{tabular}{|l|r|r|r|}
\hline AFU $\left(\leqslant 35\right.$ vs $\left.>35 \mathrm{ul}^{-1}\right)$ & $2.461(1.982-3.056)$ & $<0.001$ & $1.814(1.421-2.315)$ \\
Tumour size $(\leqslant 5$ vs $>5 \mathrm{~cm})$ & $2.116(1.692-2.646)$ & $<0.001$ & $1.549(1.208-1.985)$ \\
GGT $\left(\leqslant 64\right.$ vs $\left.>64 \mathrm{ul}^{-1}\right)$ & $1.788(1.424-2.247)$ & $<0.001$ & $1.159(0.893-1.504)$ \\
AFP $\left(\leqslant 400\right.$ vs $\left.>400 \mathrm{ng} \mathrm{ml}^{-1}\right)$ & $1.543(1.247-1.910)$ & $<0.001$ & 0.001 \\
Macrovascular invasion & $2.444(1.844-3.240)$ & $<0.001$ & 0.269 \\
ALP $\left(\leqslant 129\right.$ vs $\left.>129 \mathrm{ul}^{-1}\right)$ & $1.514(1.209-1.894)$ & $<0.001$ & $1.893(1.411-2.539)$ \\
TB $\left(\leqslant 18.8\right.$ vs $\left.>18.8 \mathrm{mmoll}^{-1}\right)$ & $1.394(1.122-1.734)$ & 0.003 & $1.095(0.859-1.395)$ \\
\end{tabular}

Validation cohort-RFS

AFU $\left(\leqslant 35 v s>\left.35 u\right|^{-1}\right)$

Tumour size $(\leqslant 5$ vs $>5 \mathrm{~cm})$

GGT ( $\leqslant 64$ vs $>64 \mathrm{ul}^{-1}$ )

AFP ( $\leqslant 400$ vs $>400 \mathrm{ng} \mathrm{ml}^{-1}$ )

$1.417(1.014-1.979)$

$1.543(1.115-2.136)$

$1.6979(1.235-2.333)$

$3.495(2.246-5.440)$

0.041

0.041

0.009

0.001

$<0.001$

$1.047(0.718-1.527)$

$1.373(0.956-1.974)$

$1.533(1.100-2.137)$

$2.805(1.756-4.480)$

0.001

0.183

0.117

0.982

Macrovascular invasion

Validation cohort-OS

AFU ( $\leqslant 35 v s>35 u^{-1}$ )

Tumour size ( $\leqslant 5$ vs $>5 \mathrm{~cm}$ )

GGT ( $\leqslant 64$ vs $>64 \mathrm{ul}^{-1}$ )

AFP ( $\leqslant 400$ vs $>400 \mathrm{ng} \mathrm{ml}^{-1}$ )

Macrovascular invasion

$\operatorname{ALP}\left(\leqslant 129\right.$ vs $>129 u^{-1}$ )

\begin{tabular}{l|r}
$4.272(2.446-7.461)$ & $<0.001$ \\
$4.292(2.246-8.202)$ & $<0.001$ \\
$2.765(1.622-4.712)$ & $<0.001$ \\
$2.112(1.329-3.357)$ & $<0.001$ \\
$4.615(2.747-7.754)$ & $<0.001$ \\
$2.063(1.271-3.348)$ & 0.003
\end{tabular}

$<0.001$
$<0.001$
$<0.001$
$<0.001$
$<0.001$
0.003

$2.333(1.249-4.369)$

$2.081(1.019-4.250)$

$1.500(0.846-2.661)$

$1.642(1.022-2.639)$

$2.352(1.289-4.289)$

$1.095(0.626-1.915)$

\begin{tabular}{r|r}
0.984 \\
0.811 \\
0.086 \\
0.012 \\
$<0.001$
\end{tabular}

Two data sets merging-RFS

AFU ( $\leqslant 35$ vs $\left.>35 \mathrm{ul}^{-1}\right)$
Tumour size $(\leqslant 5$ vs $>5 \mathrm{~cm})$
GGT $\left(\leqslant 64\right.$ vs $\left.>64 \mathrm{ul}^{-1}\right)$
AFP $\left(\leqslant 400\right.$ vs $>400 \mathrm{ng} \mathrm{ml}^{-1}$ )
Macrovascular invasion
ALP ( $\leqslant 129$ vs $\left.>129 \mathrm{ul}^{-1}\right)$

$1.782(1.509-2.104)$

1.729 (1.464-2.042)

1.524 (1.291-1.801)

1.354 (1.153-1.590)

1.827 (1.453-2.297)

1.244 (1.041-1.487)

$<0.001$

$<0.001$

$<0.001$

$<0.001$

$<0.001$

0.016

1.369 (1.134-1.653)

1.387 (1.147-1.677)

1.238 (1.028-1.489)

1.102 (0.930-1.307)

$1.516(1.195-1.924)$

0.963 (0.795-1.166)

$<0.001$

Two data sets merging-OS

AFU ( $\leqslant 35$ vs $>35 u^{-1}$ )

Tumour size ( $\leqslant 5$ vs $>5 \mathrm{~cm}$ )

GGT ( $\leqslant 64$ vs $>64 \mathrm{ul}^{-1}$ )

AFP ( $\leqslant 400$ vs $>400 \mathrm{ng} \mathrm{ml}^{-1}$ )

Macrovascular invasion

ALP ( $\leqslant 129$ vs $>129 \mathrm{ul}^{-1}$ )

TB ( $\leqslant 18.8$ vs $>18.8 \mathrm{mmoll}^{-1}$ )

Liver cirrhosis (yes vs no)

\begin{tabular}{l|r}
$2.500(2.049-3.050)$ & $<0.001$ \\
$2.229(1.808-2.747)$ & $<0.001$ \\
$1.929(1.564-2.380)$ & $<0.001$ \\
$1.664(1.371-2.020)$ & $<0.001$ \\
$2.863(2.237-3.664)$ & $<0.001$ \\
$1.636(1.334-2.007)$ & $<0.001$ \\
$1.432(1.173-1.748)$ & $<0.001$ \\
$1.326(1.043-1.687)$ & 0.021
\end{tabular}

$\begin{aligned} & <0.001 \\ < & 0.001 \\ & <0.001 \\ & <0.001 \\ & <0.001 \\ & <0.001 \\ & <0.001 \\ & 0.021\end{aligned}$

$1.724(1.376-2.160)$

$1.563(1.239-1.972)$

$1.198(0.945-1.519)$

$1.238(1.010-1.518)$

$2.018(1.557-2.615)$

$1.158(0.930-1.442)$

$1.380(1.127-1.690)$

$1.211(0.949-1.547)$

0.008
0.044
0.165
0.040
0.005
0.751

Abbreviations: $\mathrm{A}=$ absence; $\mathrm{AFP}=$ alpha-fetoprotein; $\mathrm{AFU}=$ alpha-fucosidase; $\mathrm{ALP}=$ alkaline phosphatase; $95 \% \mathrm{Cl}=95 \%$ confidence interval; $\mathrm{GGT}=\gamma$-glutamyl transpeptidase; $\mathrm{HR}=$ hazard ratio; $\mathrm{OS}=$ overall survival; $\mathrm{P}=$ presence; $\mathrm{RFS}=$ recurrence-free survival; $\mathrm{TB}=$ total bilirubin. Macrovascular invasion, $\mathrm{P}$ vs $\mathrm{A}$. The clinicopathologic variables were adopted for their prognostic significance by univariate analyses.

CI: $1.134-1.653$ and $P<0.001$; HR: 1.724 ; $95 \%$ CI: $1.376-2.160$ for RFS and OS, respectively).

Alpha-L-fucosidase in the prediction of prognosis in the training cohort. By comparing the AFU expression levels between the normal expression group and the elevated group, the cumulative 1 -, 3- and 5-year RFS rates were 56.6\%, 16.8\% and 5.1\%, respectively, in patients who had a normal AFU expression $\left(\leqslant 35 \mathrm{u} \mathrm{l}^{-1}\right)$ in the training cohort. The $1-, 3$-year RFS rate was $27.6 \%$ and $1.6 \%$, respectively $(P<0.001$; Figure $2 \mathrm{~A})$ in the 

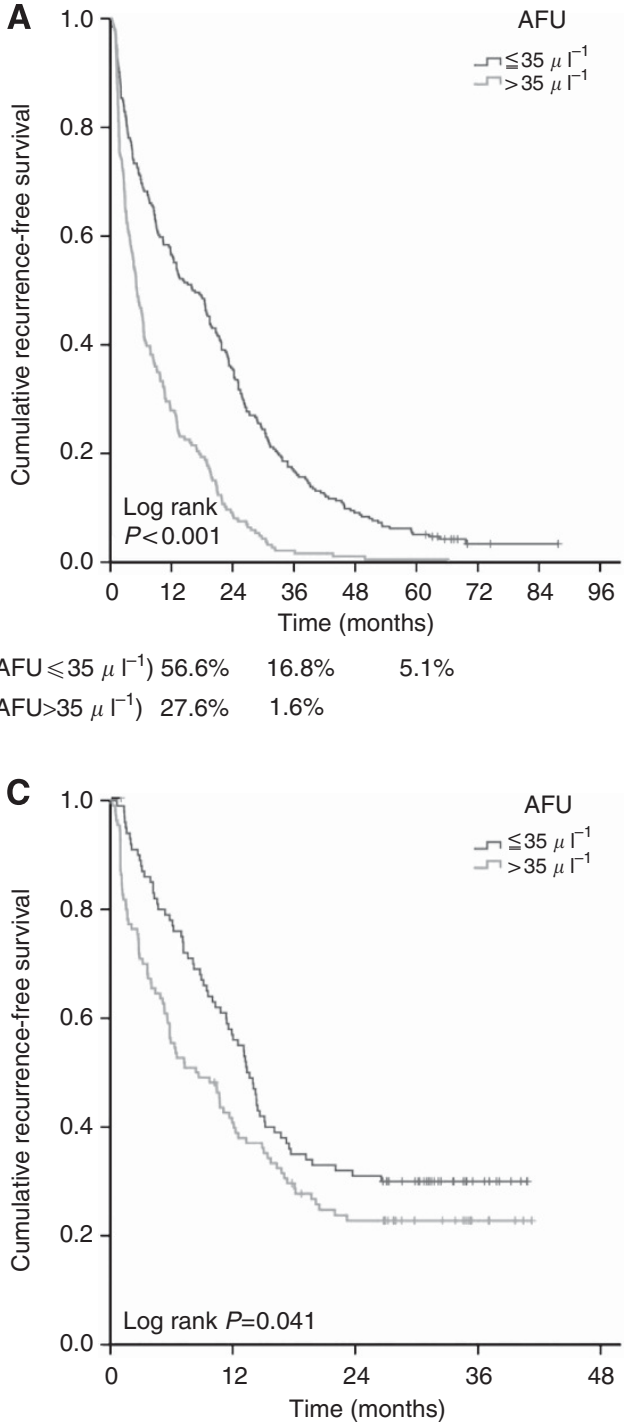

$\begin{array}{lll}\text { RFS }\left(A F U \leqslant 35 \mu l^{-1}\right) & 57.0 \% & 30.0 \% \\ \text { RFS }\left(A F U>35 \mu l^{-1}\right) & 40.8 \% & 22.8 \%\end{array}$

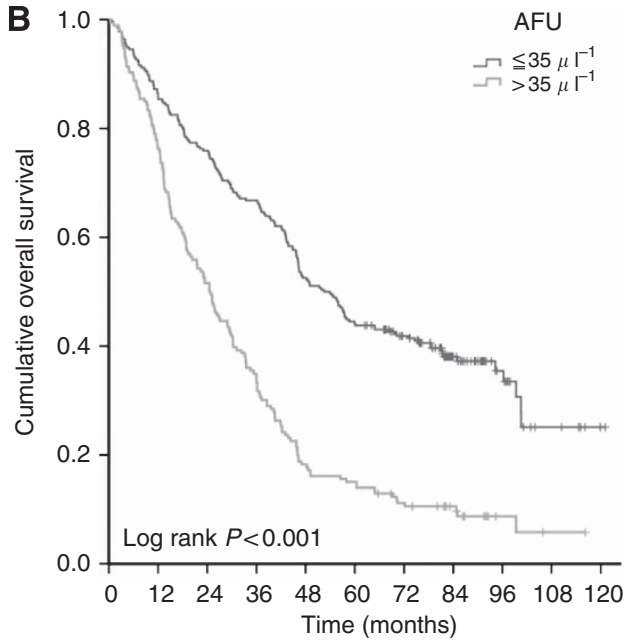

OS(AFU $\left.\leqslant 35 \mu \mathrm{I}^{-1}\right) \quad 85.8 \% \quad 66.8 \% \quad 44.2 \%$ OS(AFU $\left.>35 \mu \mathrm{I}^{-1}\right) \quad 76.2 \% \quad 33.5 \% \quad 14.6 \%$

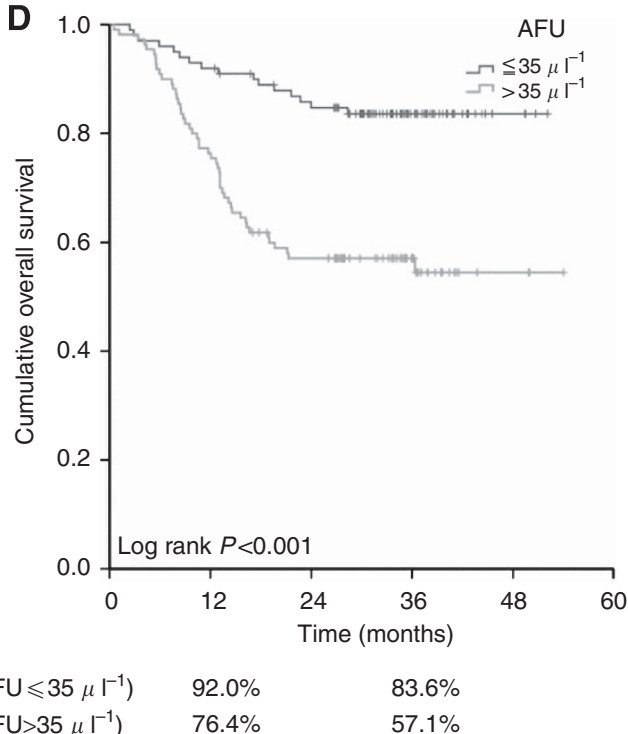

Figure 2. Kaplan-Meier analysis for RFS and OS in HCC patients with AFU $\leqslant 35 \mathrm{ul}^{-1}$ or $>35 \mathrm{ul}^{-1}$ preoperatively. (A) RFS in training cohort, (B) Overall survival in training cohort, (C) RFS in validation cohort, (D) OS in validation cohort.

group of patients with $\mathrm{AFU}>35 \mathrm{ul}^{-1}$. The cumulative $1-, 3$ - and 5-year OS rates were $85.8 \%, 66.8 \%, 44.2 \%$ and $76.2 \%, 33.5 \%, 14.6 \%$ for the AFU normal group and the AFU elevated group, respectively, in the training cohort $(P<0.001$ Figure 2B).

On univariate analysis in the training cohort using Cox's multivariate analysis (Table 2). AFU was an independent risk factor of RFS and OS $(P<0.001$; HR: 1.738 ; 95\% CI: $1.383-2.185$ and $P<0.001$; HR: 1.814 ; 95\% CI: $1.421-2.315$ for RFS and OS, respectively).

\footnotetext{
Alpha-L-fucosidase in the prediction of prognosis in the validation cohort. Similar results were obtained in the validation cohort. The cumulative 1-, 3-year RFS rates were 57.0, 30.0\% and 40.8, 22.8\% for the AFU normal group and the AFU elevated group, respectively $(P=0.041$; Figure 2C). The 1-, 3 -year OS rates were $76.4 \%, 57.1 \%$ and $92.0 \%, 83.6 \%$ for the AFU elevated group and the normal group, respectively $(P<0.001$; Figure 2D). Alpha-L-fucosidase was an independent risk factor of OS $(P=0.008$; HR: 2.333 ; $95 \%$ CI: $1.249-4.369)$ (Table 2).
}

Dynamic changes in AFU levels after surgery. The postoperative AFU levels were measured in the validation cohort on days $1,3,5$ and 1 month following partial hepatectomy. The preoperative elevated levels of AFU $>35 \mathrm{ul}^{-1}$ dropped dramatically after surgery $(100 \%, n=110$ to $13.6 \%, n=15, P<0.001$; Figure $3 \mathrm{~A}$ ) at 1 month. For the patients with preoperative normal AFU $\left(\leqslant 35 \mathrm{ul}^{-1}\right)$, there were $4.0 \%$ patients who developed high AFU levels $\left(>35 \mathrm{ul}^{-1}, 0 \%, n=0\right.$ to $4.0 \%, n=4, P=0.121$; Figure $3 \mathrm{~B}$ ) at 1 month. The number of patients who had elevated AFU levels was significantly higher in the group of patients with preoperative elevated AFU $\left(>35 \mathrm{ul}^{-1}\right)$ who had developed recurrence than the group of patients who had not developed recurrence (90.48\%, $n=76$ vs $19.20 \%, n=5, P<0.001$; Figure $3 \mathrm{C}$ ). There was no significant difference in the AFU levels between the patients who had developed recurrence or not in those patients who had preoperative normal AFU levels $\leqslant 35 \mathrm{ul}^{-1}$ (18.60\%, $n=13$ vs $13.30 \%, n=4, P=0.772$; Figure $3 \mathrm{D})$.

Preoperative AFU levels in the prediction of macrovascular invasion. The prognostic significance of preoperative AFU in the prediction of the presence of macrovascular invasion was 
A

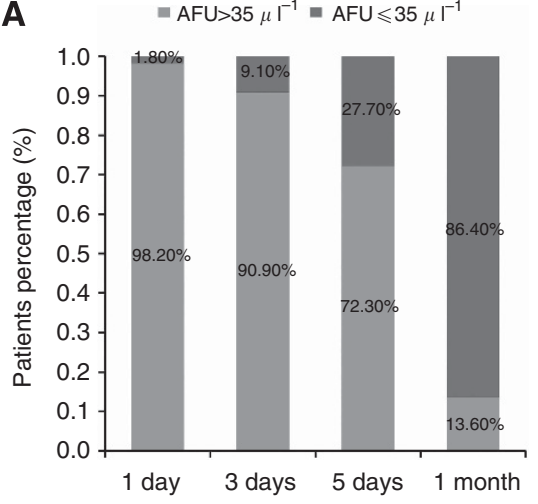

D

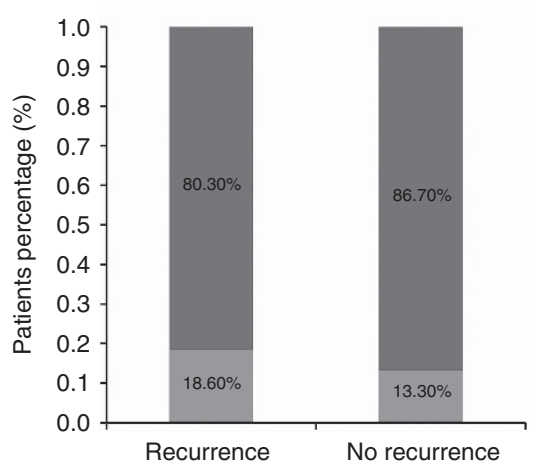

G

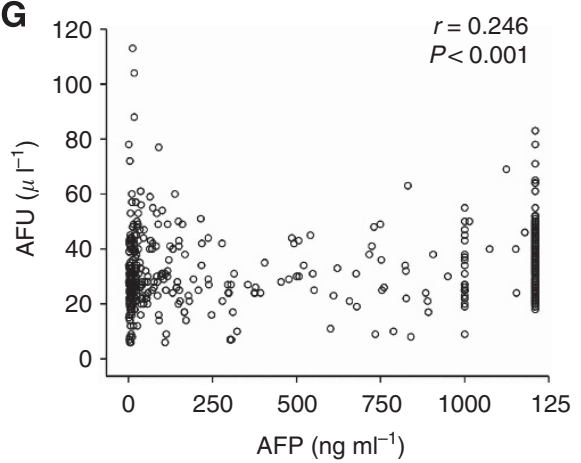

B

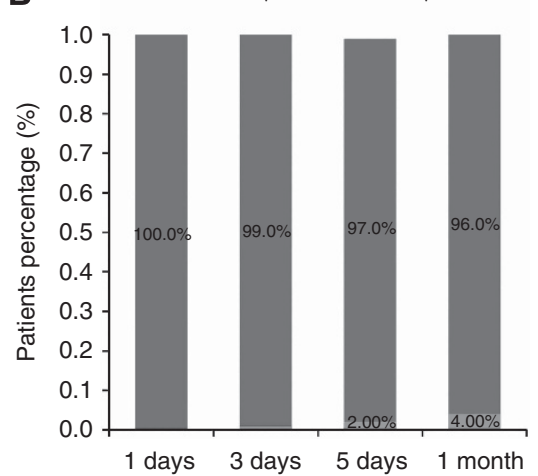

E

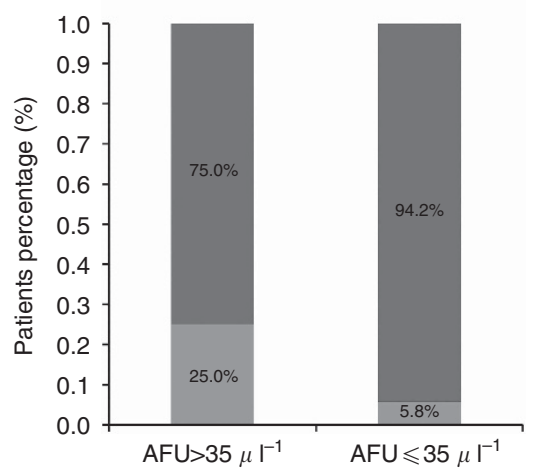

H

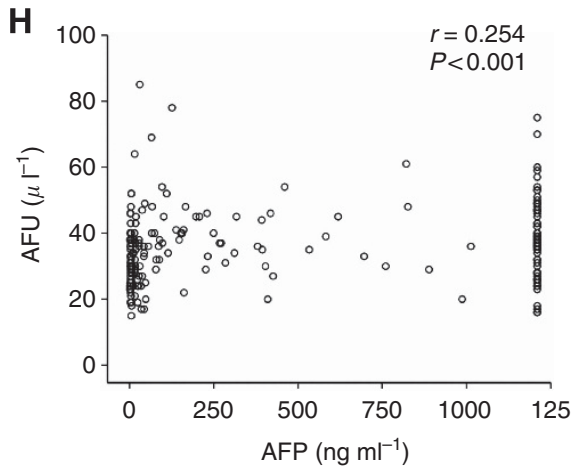

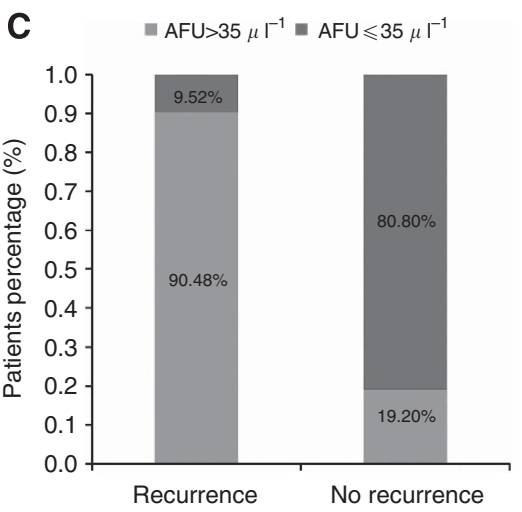

F

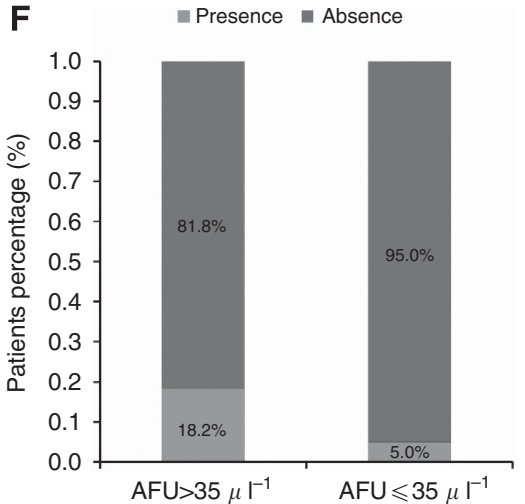

I

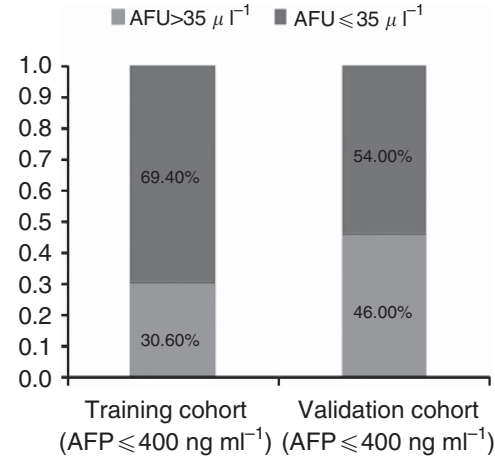

Figure 3. Changes in AFU levels reflect treatment response to HCC resection, the link between accompanying macrovascular invasion and AFU levels and the correlation between AFU level and AFP level. (A) Patients with preoperative AFU $>35 \mathrm{ul}^{-1}$ (Fisher's exact probability test, $P<0.001$ ), (B) patients with preoperative AFU $>35 \mathrm{ul}^{-1}$ at the study censored point (chi-square test, $\left.P<0.001\right)$, (C) patients with preoperative $\mathrm{AFU} \leqslant 35 \mathrm{ul}^{-1}$ (Fisher's exact probability test, $P=0.248$ ), (D) patients with preoperative AFU $\leqslant 35 \mathrm{uI}^{-1}$ at the study censored point (chi-square test, $P=0.349)$, (E) Patients in training cohort (chi-square test, $P=0.020$ ) and $(\mathbf{F})$ patients in validation cohort (chi-square test, $P=0.005),(\mathbf{G})$ The correlation between AFU level and AFP level in training cohort, $(\mathbf{H})$ the correlation between AFU level and AFP level in validation cohort, (I) the positive rate of AFU in patients with AFP $\leqslant 400 \mathrm{ng} \mathrm{ml}^{-1}$ for training cohort and validation cohort, respectively.

investigated. Patients with evaluated AFU $\left(>35 \mathrm{ul}^{-1}\right)$ had a higher incidence of macrovascular invasion $(25.0 \%, n=50$ vs $5.8 \%, n=15$, $P<0.001$ and $18.2 \%, n=20$ vs $5.0 \%, n=5, P=0.005$ in the training cohort and the validation cohort, respectively; Figure $3 \mathrm{E}$ and $\mathrm{F}$ ).

The correlation between AFU level and AFP level. By analysing the correlation between AFU level and AFP level, we found AFU level was positively correlated with the level of AFP $(r=0.246, P<0.001$ and $r=0.254, P<0.001$ for training cohort and the validation cohort, respectively; Figure $3 \mathrm{G}$ and $\mathrm{H}$ ), the positive rate of $\mathrm{AFU}$ in patients with AFP $\leqslant 400 \mathrm{ng} \mathrm{ml}^{-1}$ was $30.6 \%(76 / 248)$ and $46.0 \%$ (57/124) for training cohort and validation cohort, respectively (Figure 3I).

Prognostic significance of preoperative AFU in the clinical subgroups. The prognostic significance of preoperative AFU in the clinical subgroups was investigated by merging the training cohort data and the validation data. In patients with AFP $\leqslant 400 \mathrm{ng} \mathrm{ml}^{-1}$, patients with an AFU $>35 \mathrm{ul}^{-1}$ had a shorter time to recurrence (median of 6.51 months vs 16.59 months, $P<0.001$; Supplementary Figure S3A) and a lower survival rate $(33.1 \%, n=91$ vs $55.4 \%, n=189, P=0.004$; Supplementary Figure S4G) with shorter time to death (median of 27.2 months vs 42.94 months, $P<0.001$; Supplementary Figure S4A) than those patients with $\mathrm{AFU} \leqslant 35 \mathrm{ul}^{-1}$. Similar results were obtained in the other low recurrence risk subgroups including those subgroups with a tumour size of $\leqslant 5 \mathrm{~cm}$, absence of macrovascular invasion, gamma-glutamyl transpeptidase $(\mathrm{GGT}) \leqslant 64 \mathrm{ul}^{-1}$, and a BCLC stage of $0+$ A (Supplementary Figures S3B-G and S4B-G).

The prognostic significances of the preoperative AFU for patients with AFP $\leqslant 20 \mathrm{ng} \mathrm{ml}^{-1}$, tumour size $\leqslant 5 \mathrm{~cm}$, single tumour and absence of macrovascular invasion were investigated, 
and the results showed AFU to have significant prognostic values for these subgroups of patients in both RFS and OS (Supplementary Figure S5A and B).

\section{DISCUSSION}

This study depicts not only that a preoperative AFU level of $\leqslant 35 \mathrm{ul}^{-1}$ is a prognostic indicator associated with RFS and OS but also that it is an important prognostic indicator for clinical subgroups of patients who have a low risk of tumour recurrence and tumourrelated death, including those patients who have an AFP $\leqslant 400 \mathrm{ng} \mathrm{ml}^{-1}$, a tumour size of $\leqslant 5 \mathrm{~cm}$, a GGT $\leqslant 64 \mathrm{ul}^{-1}$, a single tumour, a BCLC stage of $0+\mathrm{A}$, and those patients absence of macrovascular invasion. Although AFU measurement has been used for the diagnosis of HCC for many years, this study provides the first evidence for the use of preoperative AFU in predicting posthepatectomy RFS and OS. The study showed that a preoperative $\mathrm{AFU} \leqslant 35 \mathrm{ul}^{-1}$ is predictive of better survival and supports the use of preoperative AFU level in monitoring treatment outcomes of HCC.

AFU is a lysosomal enzyme present in all mammalian cells. It is involved in the catabolism of fucose-containing glycoconjugates (Conchie and Hay, 1963). The use of serum AFU for the early diagnosis of HCC has previously been reported (Giardina et al, 1992; Takahashi et al, 1994; Bruix, 1997; Giardina et al, 1998), but the mechanism of elevation of serum AFU activity in HCC patients has not been determined. One possibility is an increase in protein synthesis by the neoplasm with a consequent increase in fucose turnover (Deugnier et al, 1984). However, this possibility was not supported by reports showing a significantly lower AFU level in HCC tissue compared with paired non-tumorous liver tissue (Leray et al, 1989; Hutchinson et al, 1991), which suggests that an elevated serum level of AFU was not directly derived from tumour cells (Bruix, 1997). The AFU elevation in tumour liver tissue may be a result of the decrease in enzyme degradation. Sialic acid of glycoproteins has a strong influence on its clearance rate in blood circulation, and it is possible that its change results in retarded clearance of the glycoproteins (Morell et al, 1971; Ashwell and Morell, 1974; Hutchinson et al, 1991).

In this study, we focused on the correlation of preoperative AFU level with clinical outcomes. There have been some previous observational studies on the increase in serum AFU in breast cancer patients with progressive disease, followed by a decrease with successful therapy (Thompson et al, 1992). Another study also shows that the mean value of preoperative serum AFU activity was higher in colorectal cancer (CRC) patients with distant metastases than in those with lymph node or peritoneal metastases, or without metastasis. The measurement of preoperative serum AFU activity could serve to detect hidden metastases for CRC, even before surgical intervention (Ayude et al, 2003). Most of the CRC patients with distant metastasis, for example, hepatic metastasis have a higher serum AFU level probably due to a greater flux of the enzyme from the malignant liver tissue to extracellular fluid (Deugnier et al, 1984; Takahashi et al, 1994). Our study showed HCC patients with AFU $\leqslant 35 \mathrm{ul}^{-1}$ had a better prognosis. Liver inflammation has an important role in the pathogenesis of HCC (Maeda et al, 2005; Elsharkawy and Mann, 2007). The liver contains various cell types that produce cytokines and chemokines (Leonardi et al, 2012), and these cytokines and chemokines can upregulate AFU in the later stages of inflammation. This process is consistent with activation of a natural regulatory loop, resulting in a gradual diminution of the potential of blood-borne leukocytes to penetrate the endothelium at the sites of existing inflammation (Ali et al, 2008). This anti-inflammatory/immunesuppressive response may promote HCC metastases.

Compared with before hepatic resection, the AFU activity in patients with $\mathrm{AFU}>35 \mathrm{ul}^{-1}$ had a decrease after operation.
In about 1 week to 1 month, the AFU activity decreased to normal level. Hence, positive case and positive rate also decreased. It suggests that AFU is a useful marker of HCC for post-treatment monitoring and reminds us much more attention should be taken to the patients who have hold a high AFU expression. For these patients, follow-up treatment and management strategies after operation should be concerned.

Many investigators have reported that total bilirubin, tumour size, GGT and AFP levels are related to a poor prognosis of HCC (Belghiti et al, 1991; Nagasue et al, 1993; Strasak et al, 2008a, 2008b; Wang et al, 2012). So far, AFP level is the most extensively used diagnostic biomarker and tumour recurrence indicator of HCC in AFP-positive patients (Chan et al, 2009). Clinical data demonstrated that a low serum AFP concentration (e. g. $\leqslant 400 \mathrm{ng} \mathrm{m}^{-1}$ ) is associated with better clinical outcomes. Nevertheless, it is difficult to monitor recurrence in the $30-40 \%$ of HCC patients with low AFP levels (Shah et al, 2006; Wang et al, 2009). Our results indicated the determination of the preoperative AFU level is a promising and feasibly tool for tumour recurrence and death prediction in patients with a low AFP concentration. Another way, we have shown a positively correlation between both AFU level and AFP level. Among the patients with AFP $\leqslant 400 \mathrm{ng} \mathrm{ml}^{-1}$, there were 30.6$46.0 \%$ patients with $\mathrm{AFU}>35 \mathrm{ul}^{-1}$, which may suggest the preoperative AFU level may be more useful for predicting tumour recurrence and death in patients with a low AFP concentration and high AFU level. Macrovascular invasion in patients with HCC is associated with poor survival (Shuqun et al, 2007; Shi et al, 2010). If left untreated, a median survival of $<6$ months has been reported (Llovet et al, 1999). Approximately $50-80 \%$ of HCC has been reported to be accompanied by portal or hepatic vein tumour thrombus, as demonstrated by magnetic resonance imaging and ultrasonography (Llovet and Bruix, 2008). Our result indicated that patients with preoperative serum AFU $>35 \mathrm{ul}^{-1}$ hold a higher incidence of macrovascular invasion than those with AFU $\leqslant 35 \mathrm{ul}^{-1}$, suggesting that there may be a link between AFU and macrovascular invasion.

Chronic hepatitis B virus infection is the most common cause of HCC in Asia (Chan et al, 2008). Chronic hepatitis B virus infection continues to be a major contributor to morbidity and mortality, despite the availability of vaccination programs in China and elsewhere ( $\mathrm{Li}$ et al, 2010). Our study limited to test the results in cohorts of patients with hepatitis C- or alcohol-related HCC. Moreover, our study has yet to be validated across the patients who received liver transplantation.

In conclusion, the preoperative serum AFU activity is a predictor of prognosis after hepatic resection for HCC. Patients with preoperative serum AFU $>35 \mathrm{ul}^{-1}$ have a tendency to form macrovascular invasion.

\section{ACKNOWLEDGEMENTS}

This work was supported by the grants of the Science Fund for Creative Research Groups (No.: 81221061); The China National Funds for Distinguished Young Scientists (No: 81125018); The New Excellent Talents Program of Shanghai Science and Technology Committee (No: 10XD1405800); Excellent Young Scholar Program of SMMU (No.: 20111010B); Project supported by the Natural Science Foundation of Shanghai, China (No: 12ZR1439600).

\section{CONFLICT OF INTEREST}

The authors declare no conflict of interest. 


\section{REFERENCES}

Ali S, Jenkins Y, Kirkley M, Dagkalis A, Manivannan A, Crane IJ, Kirby JA (2008) Leukocyte extravasation: an immunoregulatory role for alpha-L-fucosidase? J Immunol 181(4): 2407-2413.

Ashwell G, Morell AG (1974) The role of surface carbohydrates in the hepatic recognition and transport of circulating glycoproteins. Adv Enzymol Relat Areas Mol Biol 41(0): 99-128.

Ayude D, Paez De La Cadena M, Martinez-Zorzano VS, Fernandez-Briera A, Rodriguez-Berrocal FJ (2003) Preoperative serum alpha-L-fucosidase activity as a prognostic marker in colorectal cancer. Oncology 64(1): 36-45.

Belghiti J, Panis Y, Farges O, Benhamou JP, Fekete F (1991) Intrahepatic recurrence after resection of hepatocellular carcinoma complicating cirrhosis. Ann Surg 214(2): 114-117.

Bruix J (1997) Treatment of hepatocellular carcinoma. Hepatology 25(2): 259-262.

Bruix J, Sherman M (2011) Management of hepatocellular carcinoma: an update. Hepatology 53(3): 1020-1022.

Camp RL, Dolled-Filhart M, Rimm DL (2004) X-tile: a new bio-informatics tool for biomarker assessment and outcome-based cut-point optimization Clin Cancer Res 10(21): 7252-7259.

Chan HL, Tse CH, Mo F, Koh J, Wong VW, Wong GL, Lam Chan S, Yeo W, Sung JJ, Mok TS (2008) High viral load and hepatitis B virus subgenotype ce are associated with increased risk of hepatocellular carcinoma. J Clin Oncol 26(2): 177-182.

Chan SL, Mo FK, Johnson PJ, Hui EP, Ma BB, Ho WM, Lam KC, Chan AT, Mok TS, Yeo W (2009) New utility of an old marker: serial alphafetoprotein measurement in predicting radiologic response and survival of patients with hepatocellular carcinoma undergoing systemic chemotherapy. J Clin Oncol 27(3): 446-452.

Conchie J, Hay AJ (1963) Mammalian glycosidases. 4. The intracellular localization of beta-galactosidase, alpha-mannosidase, beta- $\mathrm{N}$-acetylglucosaminidase and alpha-L-fucosidase in mammalian tissues. Biochem J 87: 354-361.

Deugnier Y, David V, Brissot P, Mabo P, Delamaire D, Messner M, Bourel M, Legall JY (1984) Serum alpha-L-fucosidase: a new marker for the diagnosis of primary hepatic carcinoma? Hepatology 4(5): 889-892.

El-Houseini ME, Sherbiny ME, El-Din Awad MM, Amer MA, Saad El Din AH, Hussein TD (2001) Serum alpha-l-fuscosidase enzyme acrtivity as a marker for hepatocellular carcinoma: comparison with AFP using ROC Analysis. J Egypt Natl Cancer Inst 13: 277-283.

Elsharkawy AM, Mann DA (2007) Nuclear factor-kappaB and the hepatic inflammation-fibrosis-cancer axis. Hepatology 46(2): 590-597.

Ercolani G, Grazi GL, Ravaioli M, Del Gaudio M, Gardini A, Cescon M, Varotti G, Cetta F, Cavallari A (2003) Liver resection for hepatocellular carcinoma on cirrhosis: univariate and multivariate analysis of risk factors for intrahepatic recurrence. Ann Surg 237(4): 536-543.

Fawzy Montaser M, Amin Sakr M, Omar Khalifa M (2012) Alpha-L-fucosidase as a tumour marker of hepatocellular carcinoma. Arab J Gastroenterol 13(1): 9-13.

Giardina MG, Matarazzo M, Morante R, Lucariello A, Varriale A, Guardasole V, De Marco G (1998) Serum alpha-L-fucosidase activity and early detection of hepatocellular carcinoma: a prospective study of patients with cirrhosis. Cancer 83(12): 2468-2474.

Giardina MG, Matarazzo M, Varriale A, Morante R, Napoli A, Martino R (1992) Serum alpha-L-fucosidase. A useful marker in the diagnosis of hepatocellular carcinoma. Cancer 70(5): 1044-1048.

Hutchinson WL, Johnson PJ, Du MQ, Williams R (1991) Serum and tissue alpha-L-fucosidase activity in the pre-clinical and clinical stages of hepatocellular carcinoma. Clin Sci (Lond) 81(2): 177-182.

Leonardi GC, Candido S, Cervello M, Nicolosi D, Raiti F, Travali S, Spandidos DA, Libra M (2012) The tumour microenvironment in hepatocellular carcinoma (review). Int J Oncol 40(6): 1733-1747.

Leray G, Deugnier Y, Jouanolle AM, Lehry D, Bretagne JF, Campion JP, Brissot P, Le Treut A (1989) Biochemical aspects of alpha-L-fucosidase in hepatocellular carcinoma. Hepatology 9(2): 249-252.

Li LM, Hu ZB, Zhou ZX, Chen X, Liu FY, Zhang JF, Shen HB, Zhang CY, Zen K (2010) Serum microRNA profiles serve as novel biomarkers for HBV infection and diagnosis of HBV-positive hepatocarcinoma. Cancer Res 70(23): 9798-9807.
Llovet JM, Bruix J (2008) Novel advancements in the management of hepatocellular carcinoma in 2008. J Hepatol 48(Suppl 1): S20-S37.

Llovet JM, Bustamante J, Castells A, Vilana R, Ayuso Mdel C, Sala M, Bru C, Rodes J, Bruix J (1999) Natural history of untreated nonsurgical hepatocellular carcinoma: rationale for the design and evaluation of therapeutic trials. Hepatology 29(1): 62-67.

Llovet JM, Di Bisceglie AM, Bruix J, Kramer BS, Lencioni R, Zhu AX, Sherman M, Schwartz M, Lotze M, Talwalkar J, Gores GJ (2008) Design and endpoints of clinical trials in hepatocellular carcinoma. J Natl Cancer Inst 100(10): 698-711.

Maeda S, Kamata H, Luo JL, Leffert H, Karin M (2005) IKKbeta couples hepatocyte death to cytokine-driven compensatory proliferation that promotes chemical hepatocarcinogenesis. Cell 121(7): 977-990.

Malaguarnera G, Giordano M, Paladina I, Berretta M, Cappellani A, Malaguarnera M (2010) Serum markers of hepatocellular carcinoma. Dig Dis Sci 55(10): 2744-2755.

Morell AG, Gregoriadis G, Scheinberg IH, Hickman J, Ashwell G (1971) The role of sialic acid in determining the survival of glycoproteins in the circulation. J Biol Chem 246(5): 1461-1467.

Nagasue N, Uchida M, Makino Y, Takemoto Y, Yamanoi A, Hayashi T, Chang YC, Kohno H, Nakamura T, Yukaya H (1993) Incidence and factors associated with intrahepatic recurrence following resection of hepatocellular carcinoma. Gastroenterology 105(2): 488-494.

Othman AM, El-Houseini ME, El-Sofy MS, Aboul-Enein HY (2011) Potentiometric determination of alpha-L-fucosidase enzyme by using 2-chloro-4-nitrophenol-rhodamine B ion pair chemical recognition in PVC membrane sensor. Anal Bioanal Chem 400(3): 787-795.

Poon RT, Ng IO, Lau C, Yu WC, Yang ZF, Fan ST, Wong J (2002) Tumor microvessel density as a predictor of recurrence after resection of hepatocellular carcinoma: a prospective study. J Clin Oncol 20(7): $1775-1785$.

Shah SA, Greig PD, Gallinger S, Cattral MS, Dixon E, Kim RD, Taylor BR, Grant DR, Vollmer CM (2006) Factors associated with early recurrence after resection for hepatocellular carcinoma and outcomes. J Am Coll Surg 202(2): 275-283.

Shi J, Lai EC, Li N, Guo WX, Xue J, Lau WY, Wu MC, Cheng SQ (2010) Surgical treatment of hepatocellular carcinoma with portal vein tumor thrombus. Ann Surg Oncol 17(8): 2073-2080.

Shuqun C, Mengchao W, Han C, Feng S, Jiahe Y, Guanghui D, Wenming C, Peijun W, Yuxiang Z (2007) Tumor thrombus types influence the prognosis of hepatocellular carcinoma with the tumor thrombi in the portal vein. Hepatogastroenterology 54(74): 499-502.

Strasak AM, Pfeiffer RM, Klenk J, Hilbe W, Oberaigner W, Gregory M, Concin H, Diem G, Pfeiffer KP, Ruttmann E, Ulmer H (2008a) Prospective study of the association of gamma-glutamyltransferase with cancer incidence in women. Int J Cancer 123(8): 1902-1906.

Strasak AM, Rapp K, Brant LJ, Hilbe W, Gregory M, Oberaigner W, Ruttmann E, Concin H, Diem G, Pfeiffer KP, Ulmer H (2008b) Association of gamma-glutamyltransferase and risk of cancer incidence in men: a prospective study. Cancer Res 68(10): 3970-3977.

Sun YF, Xu Y, Yang XR, Guo W, Zhang X, Qiu SJ, Shi RY, Hu B, Zhou J, Fan J (2013) Circulating stem cell-like epithelial cell adhesion molecule-positive tumor cells indicate poor prognosis of hepatocellular carcinoma after curative resection. Hepatology 57(4): 1458-1468.

Takahashi H, Saibara T, Iwamura S, Tomita A, Maeda T, Onishi S, Yamamoto Y, Enzan H (1994) Serum alpha-L-fucosidase activity and tumor size in hepatocellular carcinoma. Hepatology 19(6): 1414-1417.

Tang ZY, Ye SL, Liu YK, Qin LX, Sun HC, Ye QH, Wang L, Zhou J, Qiu SJ, Li Y, Ji XN, Liu H, Xia JL, Wu ZQ, Fan J, Ma ZC, Zhou XD, Lin ZY, Liu KD (2004) A decade's studies on metastasis of hepatocellular carcinoma. J Cancer Res Clin Oncol 130(4): 187-196.

Thompson S, Cantwell BM, Matta KL, Turner GA (1992) Parallel changes in the blood levels of abnormally-fucosylated haptoglobin and alpha 1,3 fucosyltransferase in relationship to tumour burden: more evidence for a disturbance of fucose metabolism in cancer. Cancer Lett 65(2): $115-121$.

Wang CC, Iyer SG, Low JK, Lin CY, Wang SH, Lu SN, Chen CL (2009) Perioperative factors affecting long-term outcomes of 473 consecutive 
patients undergoing hepatectomy for hepatocellular carcinoma. Ann Surg Oncol 16(7): 1832-1842.

Wang Y, Chen Y, Ge N, Zhang L, Xie X, Zhang J, Chen R, Zhang B, Xia J, Gan Y, Ren Z, Ye S (2012) Prognostic significance of alphafetoprotein status in the outcome of hepatocellular carcinoma after treatment of transarterial chemoembolization. Ann Surg Oncol 19(11): 3540-3546.

Yang XR, Xu Y, Shi GM, Fan J, Zhou J, Ji Y, Sun HC, Qiu SJ, Yu B, Gao Q, He YZ, Qin WZ, Chen RX, Yang GH, Wu B, Lu Q, Wu ZQ, Tang ZY (2008) Cytokeratin 10 and cytokeratin 19: predictive markers for poor prognosis in hepatocellular carcinoma patients after curative resection. Clin Cancer Res 14(12): 3850-3859.
Yang XR, Xu Y, Yu B, Zhou J, Qiu SJ, Shi GM, Zhang BH, Wu WZ, Shi YH, Wu B, Yang GH, Ji Y, Fan J (2010) High expression levels of putative hepatic stem/progenitor cell biomarkers related to tumour angiogenesis and poor prognosis of hepatocellular carcinoma. Gut 59(7): 953-962.

Zielke K, Okada S, O’Brien JS (1972) Fucosidosis: diagnosis by serum assay of alpha-L-fucosidase. J Lab Clin Med 79(1): 164-169.

This work is published under the standard license to publish agreement. After 12 months the work will become freely available and the license terms will switch to a Creative Commons AttributionNonCommercial-Share Alike 3.0 Unported License.

Supplementary Information accompanies this paper on British Journal of Cancer website (http://www.nature.com/bjc) 